\title{
Author Index / Subject Index
}

Author Index

Bogousslavsky, J. 41

Bousser,M.G. 18

Dyken.M.L. 35

Eastern, J.D. 1,6,41

Gijn, J. van 23

Norris.J.W. 2

Sherman, D.G. 14

Subject Index

Anticoagulation 14

Antiplatelet therapy 6

Aspirin 6

Atrial fibrillation 14

Cardiogenic embolus

14

Carotid-Stenosis 2

Cerebral infarction 2

Measurement of

outcome 23

'Meta-analysislSl'

Outcome 23

Stroke 2,6,14,23,35

- prevention 6,23

Ticlopidine 6 •Trrals

r. risk 2 